\title{
The strategic process of a cultural change to implement TQM: A case study
}

\author{
ENRIQUE CLAVER, JOSÉ L. GASCÓ ${ }^{1}$, JUAN LLOPIS \& REYES \\ GONZÁLEZ \\ Department of Business Management, University of Alicante, 03080 \\ Alicante (Spain)
}

\begin{abstract}
The implementation of a TQM culture, with its implicit orientation towards the customer, is a complex matter and requires a long-term approach. Consequently, the enterprises that try to change from a bureaucratic culture to one oriented towards quality, will have to design an appropriate strategy in order to succeed. This type of modification can only be achieved through an evolutionary process and not a reactionary or a revolutionary one, since we are dealing with individual and collective behaviours that can obtain customer satisfaction through continuous improvement. In this respect, we present the case of a transformation towards a TQM culture in the Division of Alicante (Alicante is a province in the East of Spain) of Telefónica Group (a Spanish telecommunications enterprise which, in 1999, provided jobs for over 100,000 people and had profits of more than 1,780 m. $€$ ). Thus, we are going to study the stages the Division went through in the process and the problems they had to face, finally reflecting the results obtained after implementing a strategy that was formulated to achieve this purpose in the long run.
\end{abstract}

\section{Introduction}

Enterprises involved with quality must see it as an essential part of their strategic process. From this point of view, and through a case study, we intend to establish a connection between TQM and the management process that aims at a transformation from a bureaucratic culture to a quality-oriented one; all of this seen as a way to achieve a sustainable, long-term competitive advantage.

\footnotetext{
11. Correspondence: José L. Gascó, Department of Business Management, University of Alicante, San Vicente, 03080, Alicante (Spain). Tel. \& Fax: 34965903606; E-mail: jl.gasco@ua.es
} 
Regarding the strategic management process, the literature available has developed various strategy formulation models; all of them include, though, either explicitly or implicitly, the following seven steps (Hofer \& Schendel. 1978):

1. Identification with the enterprise's current strategy.

2. Analysis of the environment. It consists in the identification of potential opportunities and threats for the organisation.

3. Internal analysis. Focusing on the evaluation of the main resources and capacities available for the implementation of the strategy.

4. Analysis of the "gap". What we do is compare the organisation's resources, objectives and strategies with those necessary in order to face the opportunities and threats existing in the environment, and thus be able to determine the changes needed.

5. Strategic alternatives; a stage which is more commonly known as strategic formulation. During this stage, we try to identify the different strategic options the enterprise has at its disposal.

6. Strategy evaluation. It consists in the analysis of strategic options in terms of aims, resources, management, etc., thus identifying those options which best meet all the enterprise's requirements.

7. Strategic choice. That is to say, the selection of one or several of the previous alternatives for their later implementation and control.

Once the strategy has been determined, the next step is implementing and monitoring it. In this sense, Thompson \& Strickland (1992) say that the implementation means changing the strategic plan into a set of more specific actions, influenced by the enterprise's situation, that will later be transformed into results. In this way, every manager is responsible for the implementation of the strategy in his activity area, although it is the top management that leads the main initiative.

With the aim of implementing and later controlling these specific actions, we need to develop:

1. An organisation that is appropriate to carry out the strategy. In this respect, quality management must create a parallel structure, so that TQM is later extended to the whole organisation.

2. A corporate culture that is compatible with the strategy adopted, which we are going to call "a TQM culture" in our case. 
3. A strategic leadership that guides the whole process.

4. A set of plans, programmes and budgets which support that long-term planning.

5. An information system that helps at strategy execution and control. Communication will play a very relevant role in that system.

6. A model of rewards and incentives that helps to increase employees' motivation.

Quality has been incorporated into strategic management practice in many enterprises, once they have decided which business they want to operate in. From this point of view, TQM can become a source of competitive advantage, since, through quality improvement, it aims at providing goods or services that customers consider of a better quality than those offered by competitors. In this way, customers can choose which product to buy, among all the enterprises offering it, which will enable them to demand high quality, new technology, low prices, etc., the enterprise thus being forced to give the customer a higher value.

There is such a relationship between TQM and culture that Kanji \& Yui (1997) describe TQM as the culture of an organisation committed to customer satisfaction through continuous improvement. From this perspective, Kanji (1998) rightly states that what makes TQM different from other management processes is its concentrated focus on continuous improvement. This is why we claim that a cultural transformation from a set of bureaucratic postulates towards a TQM culture must be carried out through a long-term strategy, clearly formulated and implemented, in such a way that the change is achieved within an evolutionary process, and not within a revolutionary one. This is so because we are dealing with individual and organisational behaviours, with all the opposition that a change of this nature tends to generate. Following this line of thought, the literature claims (e.g. Bowen, 1996; Johnson, 1991; Maccoby, 1993; McNabb \& Sepic, 1995; Shirley, 1997; Sinclair \& Collins, 1994; Southern \& Murray, 1994) that the basis for the success of TQM programmes lies in analysing the culture and orienting it towards these aims.

Taking these ideas as our starting point, we are going to analyse the case of one strategic process of cultural change to implement TQM. 


\section{Telefónica Group and the Division of Alicante}

When we talk about Telefónica Group, we are referring to a parent company that exploits the basic telephone service in several countries as well as to a number of enterprises dedicated to different business activities related to telecommunications. Telefónica exploited Spain's telephone service on a monopoly basis since 1924 and until 1998, the moment in which this sector was liberalised and Telefónica started providing its service within a system based on competition. Its staff in 1999 was over 100,000 employees and its profits exceeded 1,780 m. $€$. It is the most important value in Madrid's Stock Exchange and stands on the markets of New York, Tokyo, Paris and London. Its volume of clients is above 40 million, more than half of whom are in South America. At present, it still maintains a clear leadership in Spain's telecommunications sector and has also consolidated its presence abroad.

However, before reaching this leadership position in the Spanish and Portuguese-speaking world, the enterprise has gone a long way -the same as other companies in this sector-, facing numerous transformations in its environment and undertaking important reforms in its internal management, specially during the last decade. The study of telecommunications enterprises and of how they had to adapt to their changing markets has received great attention in the literature available (e.g. Clark, 1993; Davey \& Shepherd, 1992; Graetz, 1996; Hoskinsson, Alexandre, Blackley, et al., 1998; Katz, 1995; Swierczek, 1992; Tunstall, 1986).

Among the transformations Telefónica has had to face, we must particularly underline the fact that it had to stop operating on a monopoly basis and became a competitive enterprise, which also required the abandonment of its strongly paternalistic character. This meant that the set of values all its members shared, which describe the way all its members did things in the enterprise when it came to solving problems, in short, the enterprise's culture as a whole, stopped being valid; it became necessary to project a change from a culture of subscribers to 
one of clients. One of the Group's organisational units, the Division of Alicante (Alicante is a province in Eastern Spain) played a very special role in this process of cultural change towards TQM. The results obtained there were so good that they were later extrapolated to the rest of the business group.

In 1990, Telefónica Group was a telecommunications services enterprise organised according to a double interrelated structure: provincial divisions and departments grouped together according to the areas shared. The Division of Alicante was a geographical unit directly dependent on the General Manager in charge of Exploitation (Madrid) and depended functionally on the different central departments (Madrid). At that time, it had a staff of over 1,800 employees. Since the late eighties, the Head Office (Madrid) gave it total autonomy to design, install and maintain (production), to sell, install and repair (commercial), to control expenses and investments (administration) and to engage, train and negotiate with the unions (human resources). The Head Office still kept the co-ordination of objectives and the approval of investments as well as expenses and income budgets. We must underline some characteristics about the province of Alicante and its business division:

- Although it was not one of the biggest provinces in Spain, its turnover was, after Barcelona and Madrid, one of the highest in the company (a similar position was shared by Valencia, Seville, Vizcaya and the Balearic Islands).

- In the late eighties, the growth rate in this province was far above the national average.

- There was a heavy growth of tourism-related building, in particular in the shape of residential areas outside towns, which made it more difficult to attend to the demand.

- The province had a high percentage of international calls, much more profitable than local, province or inter-province calls.

- Despite achieving a figure of 300,000 working lines, the existing demand for new lines still to be installed was, at some stage, near $70,000(23 \%)$. 
Due to all these characteristics, Alicante was a complex division at that time, but also a very profitable one with great potential for growth. These circumstances helped the Head Office's decision to approve a $92 \mathrm{~m}$. $€$ investment plan to meet the division's development needs. However, the management team in Alicante were aware of the fact that improved equipment and infrastructures would not be enough; they were convinced that structures, behaviours and values had to be modified and adapted; in short, they had to change the culture orienting it towards behaviours that were more appropriate to TQM. This idea became increasingly obvious in front of everyday problems, when training needs are assessed and the middle management's opinion is sounded out.

It was considered necessary to act on several contexts to make sure that people working in the Division of Alicante integrated into the project:

1. Training from a double perspective: knowing how to make quality (tools) and knowing how to be in quality (management style).

2. Communication as a vehicle to inform, to make things clear, to get to know each other and to avoid misunderstandings and rumours.

3. Participation in order to provide solutions to the problems that arise at each post and the will to implement those solutions.

\section{Methodology used for the cultural change towards TQM}

The Management Board understood that the cultural change was a new strategy it had to carry out. In order to guarantee its success, the implementation in the Division of Alicante had to be done through a careful planning that made possible progressive advances, with two determining factors:

- That the speed was slow enough to progressively overcome the opposition to change on part of the staff, so that they could understand the strategy and get involved in it themselves, instead of imposing it on them. 
- That the speed should be fast enough to make sure that they never put in danger either everyday management, or especially the results that, in fact, they tried to improve through this strategy.

The Management Board faces the start of the cultural change process towards TQM by successively answering these five questions:

1. Where are we?

2. What do we want to be?

3. Which principles and values must guide us?

4. How can we get there?

5. Which steps do we have to make?

These questions implicitly contain the stages in the strategic management process that we described at the beginning of this paper. Thus, a cultural diagnosis was made to answer the first question (where are we?). The results were a set of cultural components that existed, formally and informally, within the organisation. Studying all these components made it possible to establish a classification into three groups, according to their adequacy to the new TQM culture that was to be implemented. The three groups they were divided into were: to invalidate, to modify and to maintain, according to the following scheme:

To invalidate:

- Bureaucratic control systems.

- Rigid organisational charts in which there was no communication between departments, neither functionally nor operationally

- Dominance in the market based on the monopoly situation, with little knowledge or concern for subscribers' needs.

- Internal communication on an almost elementary level and always downward.

- Lack of consensus on the definition of the objectives and when spreading their achievements and the different associated problems.

To modify:

- Low level of initiatives and improvements.

- Loss of pride in belonging to the enterprise.

- Decrease in subscribers' appreciation for the enterprise.

- Low involvement level among a significant part of the staff when developing work.

To maintain:

- High levels of responsibility and professional ethics. 
- Great effort to show the service level required by society.

- The belief in the need of on-going training in order to maintain professionalism.

- A high group spirit among the existing working teams.

- A good integration level on the part of suppliers when developing work.

The answer to the second question (what do we want to be?) was the definition of their task: Being the favourite telecommunications services selling enterprise, providing the best quality recognised by customers, at the lowest possible cost for those customers.

The answer to the third question (which principles and values must guide us?) consisted in the definition of people's action guidelines throughout the process with the aim of approaching an adequate TQM; in other words, the way each employee should behave, every day, in any of their working acts:

\section{Principles:}

- The identification of the clients for the attention that they receive from the firm's human resources as well as the confidence they generate.

- Full (technical, human and social) training of our human resources.

- The appropriate use of technology. Values:

- The identification of the firm's staff with their customers.

- Responsibility and professional ethics.

- Permanent improvement in order to create efficient and agile management procedures as the global result of integrating the co-ordinated contributions of all the human potential.

- The enthusiasm and professional as well as personal satisfaction to reach a feeling of pride and membership in the company, based on the public recognition of service quality.

- Quality can be reached through the involvement of all workers with the degree of exemplarity that corresponds to each one of them.

The fourth question (how can we get there?) was solved through the design of the following strategic decisions:

1. Involving the staff through multidirectional communication.

2. Changing the ruling staff's way of working and running the firm, through training and the implementation of a new management style.

3. Optimising the human potential in keeping with the revision of the existing processes and the elaboration of a TQM plan.

4. Establishing a system of permanent improvement.

5. Co-ordinating working systems that affect several units. 
The fifth question (which steps must we make?) was answered through the formulation and implementation of five strategic objectives:

1. Creation of the Provincial Group for Quality (PGQ).

2. Design, approval and spreading of a reference document for the whole process, a document which was given the name of Firm Project for TQM (FPTQM).

3. Establishing annual Quality Plans (QPs) and obtaining the ISO 9000 certification.

4. Staff's involvement through multidirectional communication.

5. Implementation of a New Management Style in the enterprise.

The achievement of these objectives had a different time span, since some of them materialised in short, concrete periods, while others kept on developing over the years. Figure 1 shows the chronogram of the initial actions in the implementation of the cultural change process .

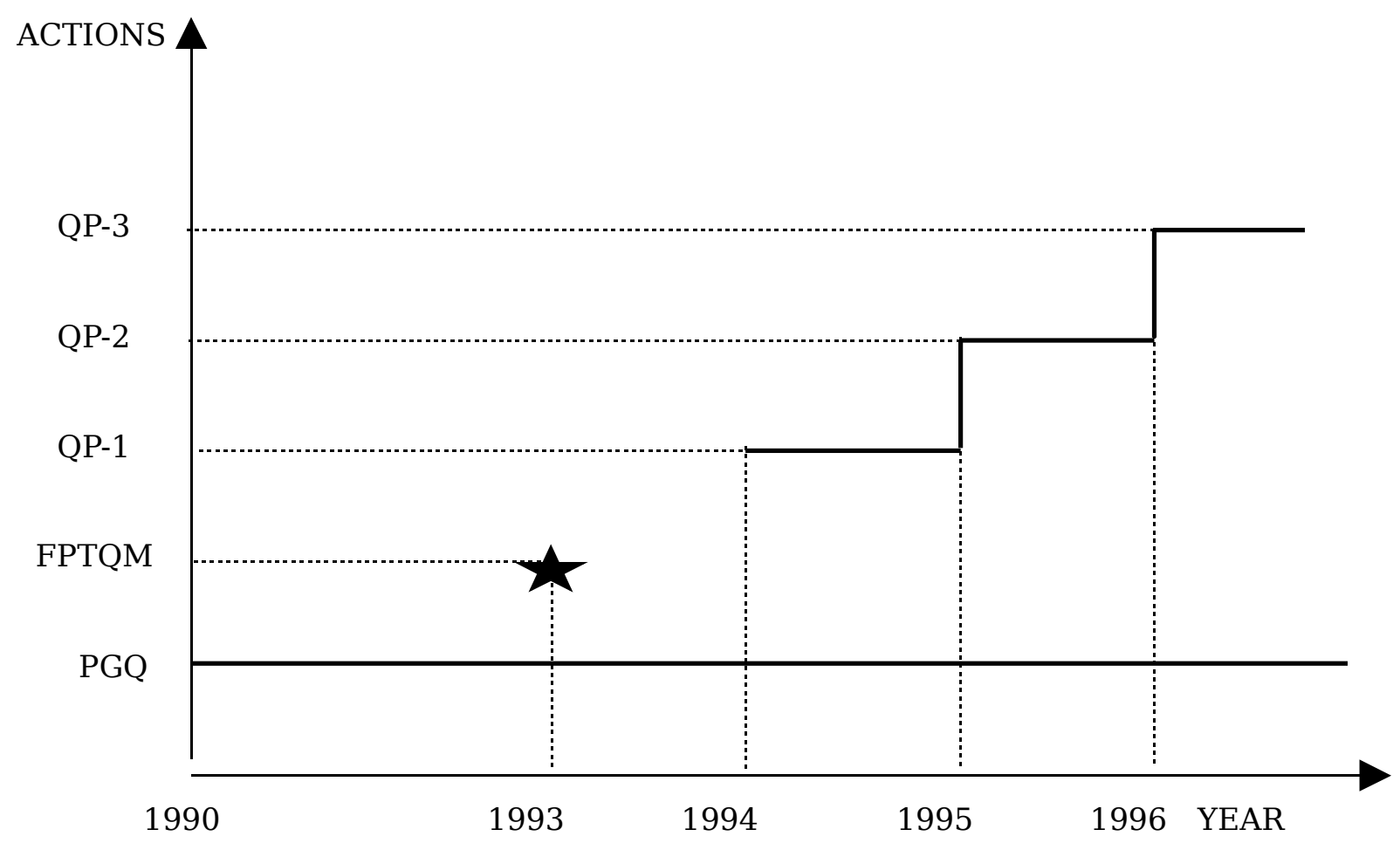

Figure 1. Performance chronology

\section{The development of strategic objectives}


Strategic Objective No.1: Creation of the Provincial Group for Quality (PGQ).

The Provincial Group for Quality was created in 1990 as a body responsible for the management of the whole process that had to lead towards TQM. It worked regularly throughout the duration of the process we are analysing. It worked as a kind of professional college and had competence over all the matters related to TQM. Its aim was constantly boosting the process towards TQM, for its implementation and to make sure that it became deeply rooted among the staff.

It was created as a functional structure, since it was meant to be the body leading the change process through its members' example and commitment. It was not given a hierarchical structure in the organisational chart, trying to avoid the sensation that its decisions were imposed upon the whole or part of the staff .

The following responsibilities were identified in order to guarantee that these objectives were fulfilled in practice:

- Leading the cultural change process through the example and the commitment with quality.

- Boosting and promoting the necessary actions in the whole organisation so that the changes needed as regards processes, use of resources, working methods as well as ways of working and running the firm, were introduced, in order to ensure that "everybody does the right thing at the right time and at the lowest possible cost ".

- Co-ordinating training for quality, from the double perspective of knowing how to make quality as regards the whole working staff, and of knowing how to be in quality as regards the whole management. This training incorporated a component of information, in the sense of providing a change in the staff's attitudes, in keeping with the cultural change that was proposed.

- Approving the documents related to quality, such as action programmes, instructions, circulars, etc. that made up the documentation corresponding to the Quality System, except for the 
Procedures and Manuals that would have to be sent to the Management Board for their approval.

- Publishing any relevant items of information about quality, both internally and externally. Generating and controlling the internal communication related to the Quality System, so that they could start shaping the attitudes and generating the confidence as well as the credibility that were essential for the cultural change.

- Keeping an active presence externally, so that the society would detect the effort being made by the enterprise in order to provide the best perceived service and at the lowest possible cost.

The PGQ was formed by the Provincial Head, the five functional viceheads and the heads of the units that had the most direct contact with customers (both external and internal); two union representatives joined in later on, in 1993.

Strategic objective No. 2. Designing a Firm Project for TQM (FPTQM). The aim was the elaboration of a document that allowed employees to share as clear a vision as possible about the strategic importance of TQM. The FPTQM contained the principles and values that the staff had to develop in their daily management, defining the cultural change it entailed and establishing the steps for its implementation within the organisation.

The FPTQM represented a commitment of the Division of Alicante with itself, integrated with the rest of the enterprise; in other words, the strategy defined in it was in accordance with that defined by Telefónica's Strategic Committee in the parent firm.

The PGQ was in charge of drawing up the FPTQM project. This body started with an internal discussion of the initial draft and in later sessions, with the aim of widening points of view in all areas, the document was sent was to almost all managers. The discussions held resulted in substantial improvements of the initial documents, which in turn gave rise to the elaboration of a second draft that could be subject to internal debate within the organisation. 
At that stage of the process, the PGQ contacted the Vice-head for Human Resources' Office, so that they could detect the problems that might arise when the staff knew the FPTQM directly. The answer was the one they expected, with numerous comments like the following:

- "It's another fashion that will go sooner or later".

- "Now, apart from working, we must make quality".

- "Once again, they have changed the way we have to do things. One simply cannot understand anything any more".

All these comments would suggest a feeling of disconnection between the staff and the sense sought by the FPTQM. In order to avoid this situation, the alternative chosen by the Vice-head for Human Resources' Office was that, before drawing up the final version of the text, the draft should be explained to all the employees, who would also be given the chance to offer suggestions for its modification.

The system designed for the communication of the document to the staff was that of waterfall-type meetings where an explanation was given about the working method that had been used in its elaboration, after which the employees' opinion on its contents was collected; following this system, the draft was sent to the staff for their consultation. After incorporating the suggestions made, they drew up the final document, which was approved by both the Division of Alicante and the Quality Department in Madrid, as they considered the document to be in harmony with the global strategy established by the Strategic Committee. The final document was made known to the whole enterprise.

Strategic Objective No.3: Establishing annual Quality Plans (QPs) and obtaining the ISO 9000 Certification.

Annual Quality Plans were documents from which an attempt was made to co-ordinate the efforts of all the organisation's members for the implementation of the FPTQM. Each plan can be seen as a reference point both for the way that had been covered until then and for the way that was yet to be covered. 
Its elaboration started by asking each area in the enterprise to carry out a self-diagnosis, identifying the key activities and choosing the characteristics that should be measured and monitored in order to determine which improvement initiatives had to be taken. They agreed that those initiatives which did not give added value to the service being delivered, from the customer's point of view, had to be dismissed.

The implementation of each plan was organised in three areas:

- Quality Construction, where they incorporated the systems and methods needed to move ahead towards the TQM culture. Training plans for quality were established and the relations between internal and external customers-suppliers were defined.

- Improving Objectives, specifying management patterns in the aspects in which the customer's needs and expectations demanded it. Two types of objectives were established: general and instrumental ones. The general objectives, which affected more than one area in the enterprise, were oriented towards the four following areas: customer satisfaction, staff satisfaction, social impact and financial results. The instrumental objectives, which were specific for each area, were oriented towards processes, activities or tasks to be carried out.

- Guaranteeing Quality, where, through a Quality Manual, the procedures were collected that helped to consolidate the systems, the methods and the objectives reached.

The PGQ secretary acted as the co-ordinator of all the information related to quality plans; more precisely, he periodically received data on the degree of fulfilment of objectives as well as information from the areas, while he told people in charge of the areas to refer back to the PGQ and sent the Management Board the modifications required for the plan's good operation.

The first quality plan was elaborated in 1994, once they had studied which the fundamental processes were, which was the most appropriate way to act on them and after defining the relationships between internal and external suppliers-clients. This first plan went through the events that had taken place until that moment, marked new objectives and explained 
how everything had developed from the very beginning, all this information being useful for the Quality Manual and other operating procedures.

Later, in 1995, the Division of Alicante obtained the ISO 9000 Certification. This was the first certification being given to a provincial division with the quality system specifically designed for telecommunications services enterprises.

Strategic Objective No. 4: Staff's Involvement through communication. The FPTQM defined internal communication as the support to transmit the decisions and actions of the whole group of workers, describing it as well as an essential tool in moving ahead towards TQM. More directly, it was placed within the actions needed to carry out the cultural change, based on the new management style and on the staff's behaviour; it also aimed at involving the whole staff in the quality process.

The PGQ paid attention to it from the very beginning. More precisely, action was carried out over three lines:

\section{A. Downward Communication:}

A system was created to transmit both the values and the principles that drove the cultural change towards TQM and the actions as well as the achievement of objectives. With this aim, were available:

- An information sheet, issued monthly, which contained all the information elaborated by the PGQ, the different working groups on quality or the functional areas.

- A quarterly report, elaborated by the sales department on the new products or services provided to external clients, for its distribution among the employees.

\section{B. Upward Communication:}

An information co-ordination system was implemented that should promote employees' creativity and initiative oriented to improving the methods and procedures used in everyday work. A system of public recognition was 
designed in order to motivate and stimulate those people who developed them. These actions were distributed in four areas:

- An annual Campaign for Quality Initiatives among all the employees.

- Detection of Non-Quality points with a corrective orientation. It was aimed at the whole staff and affected the whole working area corresponding to the Division of Alicante.

- Provincial Conferences on Quality that were held once a year. They were addressed at the structure management and the working groups. They were useful to make known initiatives and achievements related to quality. It also provided recognition for the best accomplishments.

- Opinion surveys among employees on subjects related to quality and services, both internal and external. The Vice-head for Human Resources' Office was responsible for both the elaboration and the statistical treatment of those surveys.

\section{Communication of Quality:}

The actions undertaken by the Division of Alicante, oriented towards to the implementation of the TQM process, had to be transmitted both to external and internal customers.

As far as the latter are concerned, the communication of the FPTQM to the whole staff became specially important. Similarly, once the PGQ approved it, the Quality Plan was communicated on a yearly basis: the achievements of previous years served as a source of recognition; the objectives contained in the Plan for the following year were used as a reminder of the effort that would have to be made.

Working groups were formed, with people coming from different areas and different hierarchical levels, in order to carry out this task. In the first groups that were constituted, there was always a representative of the PGQ that acted as the speaker, transmitted the Quality Plan to all the members of the group and solved all the questions that were raised about the Plan. In turn, the members of this first group would form others of a lower hierarchical level, in which the same working method was used. This process was repeated until it reached the whole staff. 
As far as internal communication was concerned, an effort was made to make sure that it was a reinforcement measure that could have an effect on those aspects considered to be the most relevant, through any communication means or channel, such as Bulletins, Circulars and other widespread documents, all of which acted as the representation of the management policy generated by the Plan.

The underlying thought was that the approaches described above would promote:

- The opening of information channels on the periodical evolution of service indicators, through internal opinion channels.

- The participation in everything that was related to quality, so that the enterprise's actions could be highlighted.

Finally, an effort was made to keep the staff informed about all those relevant items of news that arose within the community. An attempt was made, for this public recognition of Service Quality as a contribution to the development of society in a wide sense to have an influence on the staff, as was defined in the FPTQM, so that enthusiasm as well as professional and personal satisfaction could grow, which would make it possible to reach a widespread feeling of pride associated to the fact of belonging to the enterprise.

Strategic Objective No.5:The Implementation of a new management style in the enterprise.

This objective arises with the need to evolve towards a new management style. The actions that were performed, situated within the general framework of involvement on the part of all the employees, were identified along two lines:

- The design of a development programme for the top and middle management.

- Holding a Convention to design the Action Plan for 1995.

Concerning the first line, its purpose was not so much the provision of knowledge on technical and management-related topics, but instead, an effort was made in order to create more favourable and positive 
conditions so that the people concerned could "improve the job of day-today management", in accordance with those TQM parameters agreed by them all.

Therefore, the role of external trainers that were hired consisted not so much in being mere transmitters of knowledge, but rather in becoming a kind of "catalysts" that, walking next to the managers, would help to define and implement that new form of management which was needed.

During an initial stage of the programme, a diagnosis was made of the problems that managers found when "carrying out their task on a daily basis", along with the prospects for its potential evolution in the near future. Later, the great action lines were set up. All the members of the top and middle management took part in this self-diagnosis as well as in the subsequent design of the contents for the programmes. The different petitions were distributed in six training areas: definition of objectives, team work, time organisation, problem analysis, motivation and communication.

The second line was oriented towards the design of an Action Plan for 1995 with the aim, both a symbolic and a real one, of debating on it among all the members of the top and middle management, thus moving ahead towards a Convention in which the actions they would identify as the guidelines for 1995 could be agreed and written on a document. The idea they had in mind was to elaborate an action manual that would be available during that year to show which way to go.

This convention was actually an intensive day of work held in a tourist resort located 30kms away from Alicante. 189 people among top and middle management members took part in that meeting. The idea they had in mind was that the Convention should lead the participants to make a joint reflection on how to reconcile management needs and the implementation of the knowledge, the skills, the attitudes and the new values that had been considered in the different training sessions. At the same time, an attempt was made to facilitate the participation of all attendants, so that a feeling of ownership and prominent role in relation 
to the new Action Plan was generated. The implicitly underlying idea was that there is no better mobilization than that based on collective participation. The result of the Convention was the choice, after much debating and voting, of a number of actions that were to be undertaken.

At the end of this Convention, the Management Board approved a document that came to be known as Action Plan for 1995. In that Plan were fixed the actions that would obligatorily be carried out during that year, the specific objectives that were covered, the tasks that had to be fulfilled in order to implement those actions, and the time periods for their execution; simultaneously, a different person was given the responsibility for each one of them. The Vice-head for Human Resources sent this document to every member of the top and middle management, with the information about people in charge of each action and about the establishment of control mechanisms. The actions were: 1) Analysing processes; 2) Creating and using communication systems; 3) Designing and applying participation methods; 4) Providing training; 5) Spreading the culture of quality; 6) Make known the objectives and the results at each level, and 7) Promote inter-area knowledge. The whole staff had access to this document.

As a follow-up procedure for the plan, an evaluation survey was prepared for members of the top and middle management, in which each action was assessed. They evaluated themselves to what extent they had managed to carry out the different actions and achieve the various objectives, all this information being presented in a second convention in 1996.

The response rate for that survey reached $90 \%$. We know from it that $75 \%$ of the interviewees were sufficiently satisfied with the results obtained from the Action Plan and 92\% had felt supported in order to carry out that Plan. In this last respect, we must underline the support given both among the management and the employees in general at each unit.

The degree of satisfaction with the implementation of the Action Plan was quite high, although the points in which the level of satisfaction 
was low were the creation and use of communication systems and the promotion of inter-area knowledge. The following difficulties stand out among those the management had to face when they tried to carry out the plan: staff's lack of motivation 85\%; technical complexities $86 \%$; lack of directive help $74 \%$; impossibility to carry out daily tasks $88 \%$; lack of classification and specification of objectives $79 \%$.

\section{Conclusions}

In the following years, the Management of Telefónica Group decided to implement the process that had been initiated in Alicante in the rest of provincial divisions, taking into account that the results of the selfdiagnosis were almost identical in all of them. At this stage, we can state that it was an important step on the way to achieving a TQM culture and a good way of preparing the enterprise to treat its customers differently, not as it used to treat its subscribers.

Telefónica Group, in its strategic plan for the 1996-2000 period, established as its main objective that of maximising the value of the enterprise for the shareholder, passing from monopoly to leadership in an environment characterised by a growing liberalisation of the sector. We can say this objective has been achieved to a great extent. Among the factors that had contributed to this achievement we can highlight the change of behaviours which was progressively introduced in the enterprise. An important part of this change had its origin in the process initiated in Alicante.

To finish, we must say that the implementation of a TQM culture, with its implicit orientation towards the customer is a complex topic that requires a long-term approach. In the case we have studied, it is obvious that this enterprise has made enough important and necessary steps to approach that culture. In this respect, the management in Alicante considered it to be essential for the enterprise management and, above all, for the future of Telefónica and for their own professional future. This has become mainly visible in the fact that many tasks and functions have 
become more agile, and this has been perceived by customers, in such important aspects as the reduction of the waiting list until almost zero and the reduction of the time periods both for the installation and for the repair of telephone lines; the firm has also managed to increase the level as regards the perception of the way customers are treated by employees. At the end of 1995, the Division of Alicante appeared as the third most profitable one, in absolute figures, above other provinces where more lines were installed and where, consequently, more possibilities existed in terms of business turnover.

Moreover, executives are currently able to communicate better and there is a higher degree of co-ordination and co-operation between the different areas; it is also obvious that the level of commitment on the part of employees with the achievement of customer satisfaction has improved, since the employees concerned progressively stop seeing subscribers to start seeing customers, an attitude that enables the enterprise to position itself in order to compete in the telecommunications market.

\section{References}

Bowen, P.W. (1996) The need for quality cultures, Training for Quality, 42, pp. 1418.

Clark, T. (1993) AT\&T listens to customer signals, Business Marketing, 78, pp. $22-24$.

Davey, J. \& Shepherd, D. (1992) BT's wheel of fortune, Personnel Management, 24, pp. 40-43.

Graetz, F. (1996) Leading strategic change at Ericsson, Long Range Planning, 29, pp. 304-313.

Hofer, C.W. \& Schendel, D.E. (1978) Strategic formulation: Analytical concepts (St. Paul, Minnesota, West Publishing).

Hoskinsson, R.E., Alexandre, J. Blackley, T. et al. (1998) Teléfonos de México. In B. Wit \& R. Meyer (Eds.) Strategy, Process, Content, Context. An International Perspective (New York, International Thomson Business Press), pp. 11561172.

Johnson, J. (1991) The culture clock: TQM and doing the right thing right at the right time, Journal for Quality and Participation, 14, pp. 10-14.

Kanji, G.K. (1998) An innovative approach to make ISO 9000 standards more effective, Total Quality Management, 9, pp. 67-78.

Kanji, G.K. \& Yui, H. (1997) Total quality culture, Total Quality Management, 8, pp. 417-428. 
Katz, J.E. (1995) Transforming corporate culture in the US telecommunications industry: notes on social engineering, Human Systems Management, 14, pp. 21-38.

Maccoby, M. (1993) To create quality, first create the culture, ResearchTechnology Management, 36, pp. 49-51.

McNabb, D.E. \& Sepic, F.T. (1995) Culture, climate, and total quality management: Measuring readiness for change, Public Productivity \& Management Review, 18, pp. 369-385.

Shirley, B. (1997) Total Quality in ICS, The TQM Magazine, 9: pp. 29-35.

Sinclair, J. \& Collins, D. (1994) Towards a quality culture?, International Journal of Quality \& Reliability Management, 11, pp. 19-29.

Southern, G. \& Murray, A.U. (1994) Quality information management: The way to a better company culture, Information Management \& Computer Security, 2, pp. 32-35.

Swierczek, F.W. (1992) Management of change in telecommunications: A cultural approach, International Journal of Technology Management, 7, pp. 409-423.

Thompson, A.A. \& Strickland, A.J. (1992) Strategic management: Concepts and cases (Homewood, Illinois, Irwin).

Tunstall, W.B. (1986) The break-up of the Bell system: A case study in cultural transformation, California Management Review, 28, pp. 110-124. 